EESTI NSV TEADUSTE AKADEEMIA TOIMETISED. XI KÖLE

FOUSIKALIS-MATEMAATILISTE JA TEHNILISTE TEADUSTE SEERIA. 1962, NR; 3

ИЗВЕСТИЯ АКАДЕМИИ НАУК ЭСТОНСКОИ ССР. ТОМ ХІ

СЕРИЯ ФИЗИКО-МАТЕМАТИЧЕСКИХ И ТЕХНИЧЕСКИХ НАУК. 1962, № 3

\title{
РЕАКЦИОННАЯ СПОСОБНОСТЬ ОКТИЛБЕНЗОЛА
}

\author{
X. BOOPE, \\ С. ФАИНГОЛЬД, \\ кандидат технических наук
}

Реакции алкилирования ароматического ядра алкенами широко применяются в органическом синтезе. При этом закономерности присоединения алкильных групп к бензольному ядру изучены еще недостаточно. В связи с развитием промышленности поверхностноактивных веществ и в первую очередь алкиларилсульфонатов целесообразно иметь сведения о влиянии строения и длины алкильной цепи на реакционную способность алкилбензолов. В литературе имеются сведения о реакционной способ-

Таблица 1

Реакционная способность замещенных бензола

\begin{tabular}{l|c|c}
\hline & $\begin{array}{c}\text { Относительная реакцион- } \\
\text { Пая способность по } \\
\text { Производные бензола }\end{array}$ & \multicolumn{2}{|c}{ бензолу } \\
\cline { 2 - 3 } & Лебедеву & Кондону \\
\hline & 1 & 1 \\
Бензол & 2,24 & 2,09 \\
Толуол & 2,09 & 1,73 \\
Этилбензол & 1,85 & 1,70 \\
Изопропилбензол & 1,69 & - \\
Вторичный бутилбензол & 1,45 & 1,23 \\
Третичный бутилбензол & 1,82 & - \\
Фенилциклогексан & 3,23 & - \\
м-Ксилол & 2,73 & - \\
р-Ксилол & 1,63 & - \\
Дифенил & 2,02 & - \\
Дифенилметан & 2,75 & - \\
1,2-Дифенилэтан & 2,81 & - \\
1,4-Дифенилэтан & 3,14 & - \\
Нафталин & 0,283 & - \\
Фторбензол & 0,114 & - \\
Хлорбензол & 0,097 & - \\
Бромбензол & 0,202 & - \\
о-Хлортолуол & 0,205 & - \\
м-Хлортолуол & 0,134 & - \\
р-Хлортолуол & 1,27 & - \\
Анизол & & \\
& &
\end{tabular}


ности алкилбензолов с боковой цепью до $\mathrm{C}_{4}[1,2,3]$. Эти закономерности не применимы к алкилбензолам с более длинной цепью, так как с увеличением длины алкильной цепи появляются пространственные затруднения, препятствующие дальнейшему присоединению алкильных групп.

Целью настояшей работы было изучение реакционной способности октилбензола в реакции алкилирования его алкенами в присутствин хлористого алюминия.

Углеводородный алифати́ческий радикал принадлежит к заместителям первого рода, и наличие его в ядре должно повышать реакционную способность бензольного ядра $\left.{ }^{4}\right]$. Тем не менее, изучая реакции алкилирования, мы встречались с отклонениями от этого правила, что послужило толчком для постановки более детального исследования.

Реакционная способность низших гомологов бензола по Қондону, Брауну и Лебедеву больше, чем бензола (см. табл. 1) [1, 2, 5].

Введение в ароматическое ядро одной или более алкильных групп увеличивает его реакционную способность. При этом удлинение или разветвление алкильных групп уменьшает их активирующее действие

$$
\mathrm{CH}_{3}>\mathrm{C}_{2} \mathrm{H}_{5}>\left(\mathrm{CH}_{3}\right)_{2} \mathrm{CH}>\mathrm{CH}_{3}-\mathrm{CH}>\left(\mathrm{CH}_{3}\right)_{3} \mathrm{C}
$$

Противоположные результаты получил Плюснин с сотрудниками [3]. По их данным, введение алкнльной группы, начиная с изопропильной, снижает реакционную способность бензольного ядра.

Влияние строения алкилирующего агента на реакционную способность ароматических углеводородов изучал Браун с сотрудниками $\left[{ }^{6}, 7\right.$. Ими была определена относительная реакционная способность толуола и бензола $k_{\text {тол }} / k_{\text {бенз }}$ в реакциях алкилирования бромистым метилом, бромистым этилом и изопропилбромидом. При совместном алкилировании смесей бензола и толуола в соотношении 1:1 получены относительные скорости реакІци, приведенные в табл. 2.

\section{Таблица 2}

\section{Реакционная способность толуола в зависимости от алкилирующих агентов}

\begin{tabular}{|c|c|}
\hline $\begin{array}{c}\text { Алкилирующий } \\
\text { агент }\end{array}$ & $\begin{array}{c}\text { Относительная } \\
\text { скорость } \\
k_{\text {тол }} / k_{6 \mathrm{eн3}}\end{array}$ \\
\hline $\begin{array}{l}\text { Метилбромид } \\
\text { Этилбромид } \\
\text { Изопропилбромид }\end{array}$ & $\begin{array}{l}2,95 \\
2,4 \\
1,65\end{array}$ \\
\hline
\end{tabular}

Как видно из таблицы, по Брауну, реакционная способность толуола уменьшается с удлинением и разветвлением цепи алкилирующего алкилгалоида, т. е. с увеличением его реакщионной способности.

Лебедев определил относительные скорости реакции толуола и бензола при алкилировании разными алкилирующими агентами и пришел к выводу, что наибольшее различие в относительной скорости алкилирования толуола и бензола наблюдается при более активных замещающих агентах [10]. 


\section{Методика определения реакционной способности}

Определение реакционной способности может быть осуществлено тремя методами:

1. Непосредственные кинетические измерения скорости алкилирования бензола и исследуемого алкилбензола $\left[{ }^{[8]}\right.$.

2. Изучение состава продуктов совместного алкилирования смесей бензола и исследуемого алкилбензола $\left[{ }^{9}, 10\right]$.

3. Изучение состава продуктов последовательного алкилирования. Метод Плюснина $[3,11,12,13]$.

Первый метод неприменим в связи с отсутствием удовлетворительного метода наблюдения за ходом реакции. Этот метод применим для определения скоростей реакции при алкилировании алкилгалоидами. Основным критерием является кинетика выделения хлористого водорода.

При использовании метода совместного алкилирования определяется количество прсдуктов реакции алкилирования смеси бензола и исследуемого алкилбензола, а относительная скорость реакции высчитывается по формуле [14].

$$
\frac{k_{y}}{k_{x}}=\frac{\log \left(y / y_{t}\right)}{\log \left(x / x_{t}\right)}
$$

где

$$
y_{t}=y-\Delta y \quad x_{t}=x-\Delta x
$$

$k_{x}$ - константа скорости алкилирования бензола;

$k_{y}$ - константа скорости алкилирования исследуемого алкилбензола;

$y$ - количество исследуемого алкилбензола в молях в начале реакции;

$x$ - количество бензола в молях в начале реакции;

$\Delta y$ - количество продукта алкилирования исследуемого алкилбензола после реакции в молях;

$\Delta x$ - количество продукта алкилирования бензола после реакции в молях.

Метод совместного алкилирования весьма эффективен для определения реакционной способности алкилбензолов с короткой боковой цепью. При определении по этому методу реакционной способности алкилбензолов с алкильной цепью выше восьми атомов углерода имеются затруднения, связанные с трудностью определения содержания диалкилароматических углеводородов в продуктах реакции.

Третий метод основан на предположении последовательного образования алкилбензолов по схеме

бензол $\stackrel{k}{\longrightarrow}$ моно $\stackrel{\boldsymbol{k}_{2}}{\rightarrow}$ ди $\stackrel{\boldsymbol{k}_{3}}{\longrightarrow}$ трн $\stackrel{\boldsymbol{k}_{4}}{\longrightarrow}$ тетра $\stackrel{\boldsymbol{k}_{5}}{\longrightarrow}$ пента $\stackrel{\boldsymbol{k}_{6}}{\longrightarrow}$ гексаалкилбензол.

Если начальное количество бензола в системе С молей, то к моменту $t$ часть бензола $\mathrm{X}_{1}$ молей перейдет в моноалкилбензол и в системе останется бензола $\mathrm{C}_{0}=\mathrm{C}-\mathrm{X}_{1}$.

В результате второй реакции к моменту $t$ часть моноалкилбензола $\mathrm{X}_{2}$ перейдет в диалкнлбензол и в системе останется моноалкилбензола $\mathrm{C}_{1}=\mathrm{X}_{1}-\mathrm{X}_{2}$.

Из диалкилбензола $\mathrm{X}_{2}$ часть, равная $\mathrm{X}_{3}$ перейдет в триалкилбензол и в системе останется диалкилбензола $\mathrm{C}_{2}=\mathrm{X}_{2}-\mathrm{X}_{3}$.

Таким образом, к моменту $t$ в системе будет:

$$
\begin{array}{ll}
\text { триалкилбензола } & \mathrm{C}_{3}=\mathrm{X}_{3}-\mathrm{X}_{4} \\
\text { тетраалкилбензола } & \mathrm{C}_{4}=\mathrm{X}_{4}-\mathrm{X}_{5} \\
\text { пентаалкилбензола } & \mathrm{C}_{5}=\mathrm{X}_{5}-\mathrm{X}_{6} \\
\text { гексаалкилбензола } & \mathrm{C}_{6}=\mathrm{X}_{6} .
\end{array}
$$

Скорость образования каждого из компонентов системы может быть выражена следующими дифференциальными уравнениями:

$$
\begin{gathered}
\frac{d x_{1}}{d t}=k_{1}\left(c-x_{1}\right)=k\left(c-x_{1}\right) \\
\frac{d x_{2}}{d t}=k_{2}\left(x_{1}-x_{2}\right)=a k\left(x_{1}-x_{2}\right) \\
\frac{d x_{3}}{d t}=k_{3}\left(x_{2}-x_{3}\right)=b k\left(x_{2}-x_{3}\right) \\
. . . . . . . . \\
\frac{d x_{6}}{d t}=k_{6}\left(x_{5}-x_{6}\right)=t k\left(x_{6}-x_{5}\right) .
\end{gathered}
$$


Соотношение между скоростями реакций обычно выражается постоянными $k_{1}: k_{2}: k_{3}: k_{4}: k_{5}: k_{6}=1: a: b: d: g: l$, а концентрация компонентов в системе в молярных процентах.

Интегрируя уравнения при $\mathrm{C}=100$ и подставляя в уравнения концентрации компонентов системы, получаем:

$\mathrm{C}_{0}=100 e^{-k t}$

$\mathrm{C}_{1}=\frac{100}{a-1}\left(e^{-k t}-e^{-a k t}\right)$

$\mathrm{C}_{2}=100\left[\frac{a}{(a-1)(b-1)} e^{-k t}-\frac{a}{(a-1)(b-a)} e^{-a k t}-\frac{a}{(b-1)(b-a)} e^{-b k t}\right]$

$\mathrm{C}_{3}=100\left[\frac{a b}{(a-1)(b-1)(d-1)} e^{-k t}-\frac{b d}{(a-1)(b-a)(d-a)} e^{-a k t}+\frac{a b}{(b-1)(b-a)(d-b)} e^{-b k t}\right]$ $+\left[1-\frac{a b d}{(a-1)(b-1)(d-1)}+\frac{b d}{(a-1)(b-a)(d-a)}+\frac{a d}{(b-1)(b-a)(d-b)}\right] e^{-d k t}$

Состав системы к моменту $t$ определяется экспериментальным путем.

Из первого уравнения следует, что $k t=\ln \frac{100}{\mathrm{C}_{0}}$. Заменяя $k t$ на $\ln \frac{100}{\mathrm{C}_{0}}$ и подставляя вместо $\mathrm{C}_{0}$ и $\mathrm{C}_{1}$ соответствующие значения молярных концентраций, полученных из опыта, можно из второго уравнения определить постоянную $а$. При известном значении $a$ и $\mathrm{C}_{2}$ определяется постоянная $b$ и т. д.

Метод Плюснина в сочетании с методом совместного алкилирования позволяет получить более или менее достоверные результаты.

Кроме того, в ходе изучения реакционной способности алкилбензолов по методу Плюснина определяются оптимальные условия алкилирования с целью максимального получения моноалкилпронзводных.

\section{Экспериментальная часть}

\section{Получение исходных олефинов}

Индивидуальные олефнновые углеводороды с двойной связью в $\alpha$ положении получались из первичных спиртов дегидратацией на активированной окиси алюминия и өректификацией на колонне с 125 теоретическими тарелками. Температура дегидратации $360^{\circ}$. Объемная скорость 0,8 л спирта на 1 л катализатора в час. Свойства алкенов-1 приведены в табл. 3.

Таблица 3

Показатели алкенов-1

\begin{tabular}{|c|c|c|c|c|}
\hline \multirow[b]{2}{*}{ Показатели } & \multicolumn{2}{|c|}{ пентен-1 } & \multicolumn{2}{|c|}{ октен-1 } \\
\hline & Определ. & $\begin{array}{l}\text { Литерат. } \\
\text { данные }\end{array}$ & Определ. & $\begin{array}{l}\text { Литерат. } \\
\text { данные }\end{array}$ \\
\hline Температура кипения, ${ }^{\circ} \mathrm{C}$ & 30,0 & 29,97 & & $122,3-$ \\
\hline Удельный вес $d_{4}^{20}$ & 0,6405 & 0,6405 & $\begin{array}{r}122,5 \\
0,7154\end{array}$ & $\begin{array}{l}122,5 \\
0,7149\end{array}$ \\
\hline Показатель преломления $n_{\mathrm{D}}^{20}$ & 1,3720 & 1,3715 & $\begin{array}{c}1,4101- \\
1,4103\end{array}$ & $1,4097-$ \\
\hline Содержание олефина-1, \% & 99,98 & - & 99,5 & - \\
\hline
\end{tabular}




\section{Изучение реакционной способности октилбензола методом совместного алкилирования}

Изучение проводилось путем алкилирования пентеном-1 смеси бензола и октилбензола, взятых в молярном соотношении 1:1. Для устранения реакций деалкирования и диспропорцонирования алкильных групп процесс проводился в присутствии 10\% раствора хлористого алюминия в нитробензоле.

Для алкилирования были применены химически чистый бензол (бессернистый) и октилбензол, синтезированный методом алкилирования из бензола и октена-1. Показатели исходных веществ приведены в табл. 4.

\section{Таблица 4}

Показатели исходных веществ

\begin{tabular}{l|c|c|c}
\hline $\begin{array}{l}\text { Исходное } \\
\text { вещество }\end{array}$ & $\begin{array}{c}\text { Tемперату- } \\
\text { ра кипения, } \\
{ }^{\circ} \mathrm{C}\end{array}$ & $\begin{array}{c}\text { Удельный } \\
\text { вес } d_{4}^{20}\end{array}$ & $\begin{array}{c}\text { Показатель } \\
\text { преломле- } \\
\text { ния } n_{\mathrm{D}}^{20}\end{array}$ \\
\hline Бензол & 80,1 & 0,877 & 1,5011 \\
Октилбензол & $248-252$ & 0,8559 & 1,4840 \\
Нитробензол & $210-211$ & 1,2030 & 1,5524
\end{tabular}

Температура реакции $35^{\circ}$. Скорость прибавления олефина 18 мл/час. Ректификадия полученного алкилата осуществлялась на колонке с 40 теоретическими тарелками.

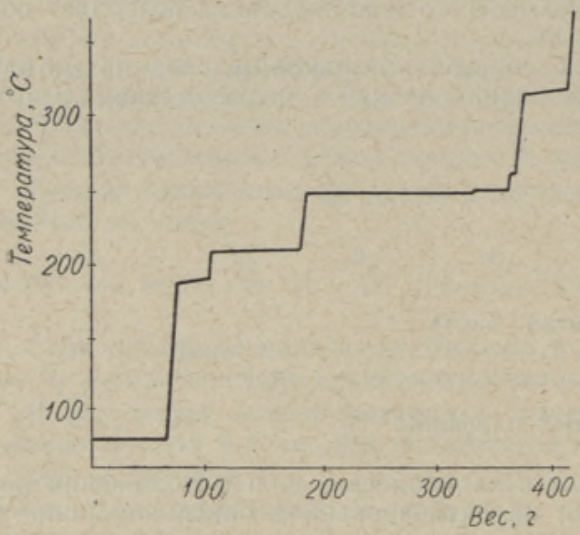

Кривая ректификации алкилата приведена на фиг. 1 , а сводка материальных балансов в табл. 5 .

Значение относительной скорости реакции алкилирования октилбензола $k_{y} / k_{x}$, рассчитанное по формуле (1) (см. стр. 214) составляет 0,753 .

Таким образом, в реакции алкилирования бензольного ядра пентеном-1, введение октильной группы снижает реакционную способность ядра.

Фиг. 1.

Таблица 5

Материальный баланс алкилирования смеси бензола и октилбензола пентеном-1

\begin{tabular}{|c|c|c|c|c|c|c|c|c|c|}
\hline Статьи баланса & 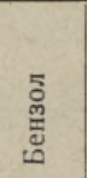 & 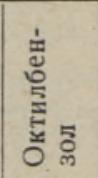 & 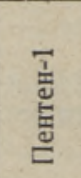 & 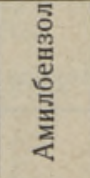 & 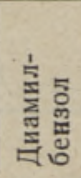 & 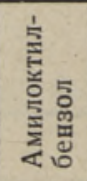 & $\begin{array}{l}\text { 응 } \\
\text { 을 } \\
\text { 至。 }\end{array}$ & 竎 & : \\
\hline $\begin{array}{c}\text { Взято для алкилирова- } \\
\text { ния, г }\end{array}$ & 96 & 242 , & 48, & & & & 93,3 & - & 483,92 \\
\hline $\begin{array}{l}\mathrm{r} \cdot \text { моль } \\
\text { Взято для ректификации, } \\
\mathrm{r}\end{array}$ & & & 06 & & & & & & 433,39 \\
\hline $\begin{array}{l}\text { Получено после ректи- } \\
\text { фикации, r } \\
\text { Выходы продуктов в рас- }\end{array}$ & 71,10 & 183,00 & - & 34,05 & 1,5 & 46,20 & 83,56 & 13,94 & 433,39 \\
\hline $\begin{array}{l}\text { чете на весь ал } \\
\text { г моль }\end{array}$ & $\begin{array}{l}79,38 \\
1,018\end{array}$ & $\begin{array}{r}204,33 \\
1,076\end{array}$ & & $\begin{array}{l}37,99 \\
0,257\end{array}$ & $\begin{array}{l}1,70 \\
0,008\end{array}$ & $\begin{array}{l}51,60 \\
0,198\end{array}$ & 93,30 & $\begin{array}{l}15,56 \\
0,222\end{array}$ & 83 \\
\hline
\end{tabular}


Изучение реакционной способности октилбензола методом последовательного алкилирования (метод Плюснина)

При алкилировании бензола октеном не образуются октилбензолы с числом алкильных групп выше двух [3]. Реакция идет только в две стадии и поэтому используются только первые три уравнения [3].

Для определения константы скоростей реакции образования октилбензола и диоктилбензола проведены исследования процесса алкилирования бензола октеном-1 при молярных соотношениях бензол : октен-1 от 1 до 8.

Катализатором служил $10 \%$ раствор хлористого алюминия в нитробензоле. Количество хлористого алюминия составляло $15 \%$ от октена-1. Для сохранения постоянства состава среды при изменении концентрации бензола добавлялся инертный растворитель декалин.

Температура алкилирования $35^{\circ}$. Скорость прибавления октена-1 15 мл/час.

Содержание компонентов в продуктах реакции устанавливалось ректификацией на вакуумной колонке с погоноразделительной способностью 30 теоретических тарелок. Для количественного определения компонентов и полного удаления октилбензола в куб колонки загружался цетан с началом кипения $132^{\circ}$ при 10 мм рт. ст. Содержание диоктилбензола устанавливалось из уравнений материального баланса:

по бензолу $\frac{78}{M_{1}} \mathrm{P}_{1}+\frac{78}{\mathrm{M}_{2}} \mathrm{P}_{2}+\mathrm{P}_{0}=100-\mathrm{y}$

по октену-1 $\frac{112}{\mathrm{M}_{1}} \mathrm{P}_{1}+\frac{2 \cdot 112}{\mathrm{M}_{2}} \mathrm{P}_{2}+\mathrm{p}=\mathrm{y}$,

где

$M_{1}$ и $M_{2}$ молекулярные веса моно- и диоктилбензола;

$\mathrm{P}_{0}, \mathrm{P}_{1}, \mathrm{P}_{2}$ и р соответственные весовые проценты бензола, моно-, диоктилбензола и полимеров в смеси;

y - весовой процент октена-1 в смеси.

Таблица 6

Полимеризация алкена в процессе алкилирования

\begin{tabular}{l|r|r|r|r|r|r|r}
\hline Показатели полимеризации & \multicolumn{5}{|c}{ Молярное соотношение октен : бензол } \\
\cline { 2 - 8 } & 0,125 & 0,1615 & 0,240 & 0,3445 & 0,472 & 0,989 & 1,016 \\
\hline $\begin{array}{l}\text { Содержание полимеров в ал- } \\
\text { килате, вес. \% }\end{array}$ & 0,54 & 2,05 & 6,37 & 8,10 & 12,4 & 29,20 & 30,6 \\
$\begin{array}{l}\text { Количество полимеризованно- } \\
\text { го октена, вес. \% от исход- } \\
\text { ного }\end{array}$ & 3,51 & 10,9 & 24,9 & 24,4 & 30,7 & 49,7 & 51,8
\end{tabular}

Для проверки полученных результатов при молярном соотношении октен-1: бензол $1: 1$ содержание диоктилбензола в остатке ректификации определялось методом хроматографического промывания.

Таблица 7

Относительное содержание различных продуктов реакции, вес. \%

\begin{tabular}{|c|c|c|c|}
\hline $\begin{array}{c}\text { Молярное } \\
\text { отношение } \\
\text { октен-1 : бензол }\end{array}$ & 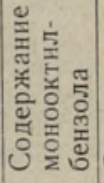 & 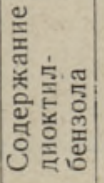 & 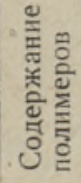 \\
\hline $\begin{array}{ll}0,125 & (1: 8) \\
0,161 & (1: 6) \\
0,24 & (1: 4) \\
0,34 & (1: 3) \\
0,47 & (1: 2) \\
0,985 & (1: 1)\end{array}$ & $\mid \begin{array}{l}89,73 \\
80,13 \\
72,9 \\
70,6 \\
58,7 \\
39,1\end{array}$ & $\begin{array}{l}7,67 \\
13,05 \\
10,4 \\
12,9 \\
19,5 \\
20,3\end{array}$ & $\begin{array}{c}2,6 \\
6,82 \\
16,7 \\
16,5 \\
21.8 \\
40.5\end{array}$ \\
\hline
\end{tabular}


Кроме образования моно- и диоктилбензола существенную роль в этом процессе нграют реакции полимеризации.

В табл. 6 приведены данные о полимеризации октена-1 в зависимости от соотношения октен-бензол.

При эквимолярных соотношениях октена и бензола колнчество полимеризующихся олефиновых углеводородов весьма велико. В табл. 7 приведены сведения о распределении продуктов реакции в зависимости от молярного соотношения алкен: бензол.

Эти данные показывают, что увеличение молярного отношения алкен: бензол не столько увеличивает выход диалкилароматических углеводородов, сколько приводит к резкому увеличению выхода полимерных продуктов.

Следует отметить, что полимеризация алкенов является параллельной реакцией и не влияет на константы скорости образования алкилбензолов [3]. Состав алкилата за вычетом полимерных продуктов в зависимости от взятого для-алкилирования молярного соотношения оқтен-1-бензол и исправленного молярного соотношения, соответствующего количеству фактически израсходованного октена-1 на образование алкилбензолов приведены в табл. 8. При использовании результатов табл. 8 в соответст-

Таблица 8

Состав алкилата

\begin{tabular}{|c|c|c|c|c|c|}
\hline \multicolumn{2}{|c|}{ Молярное соотношение } & \multirow[b]{2}{*}{$\begin{array}{c}\text { Содержание } \\
\text { бензола, } \\
\text { вес. \% } \\
\left(\mathrm{P}_{0}\right)\end{array}$} & \multirow[b]{2}{*}{$\begin{array}{c}\text { Содержание } \\
\text { октил- } \\
\text { бензола, } \\
\text { вес. \% } \\
\left(\mathrm{P}_{1}\right)\end{array}$} & \multirow[b]{2}{*}{$\begin{array}{c}\text { Содержание } \\
\text { диоктил- } \\
\text { бензола, } \\
\text { вес. \% } \\
\left(\mathrm{P}_{2}\right)\end{array}$} & \multirow[b]{2}{*}{$\begin{array}{r}\text { Отношение } \\
\text { выходов мо- } \\
\text { нооктилбен- } \\
\text { зола к диок- } \\
\text { тилбензолу }\end{array}$} \\
\hline октен : бензол & $\begin{array}{l}\text { октен : бензол, } \\
\text { за вычетом ок- } \\
\text { тена, израсхо- } \\
\text { дованного на } \\
\text { полимеризацню }\end{array}$ & & & & \\
\hline $\begin{array}{l}0,125 \\
0,161 \\
0,240 \\
0,345 \\
0,472 \\
0,985 \\
0,989\end{array}$ & $\begin{array}{l}0,121 \\
0,144 \\
0,179 \\
0,262 \\
0,326 \\
0,490 \\
0,500\end{array}$ & $\begin{array}{l}75,5 \\
72,0 \\
66,0 \\
55,3 \\
49,3 \\
35,4 \\
35,2\end{array}$ & $\begin{array}{l}22,6 \\
24,1 \\
29,8 \\
37,8 \\
38,3 \\
42,5 \\
42,7\end{array}$ & $\begin{array}{r}1,9 \\
3,9 \\
4,2 \\
6,9 \\
12,4 \\
22,1 \\
22,1\end{array}$ & $\begin{array}{l}11,7 \\
6,15 \\
7,02 \\
5,45 \\
3,01 \\
1,93 \\
-\end{array}$ \\
\hline
\end{tabular}

вии с методикой расчета, изложенной выше, было определено отношение констант скоростей реакции образования октилбензола и диоктилб́ензола, Кривые зависимости состава алкилата от молярного соотношения исходных компонентов, представленные на

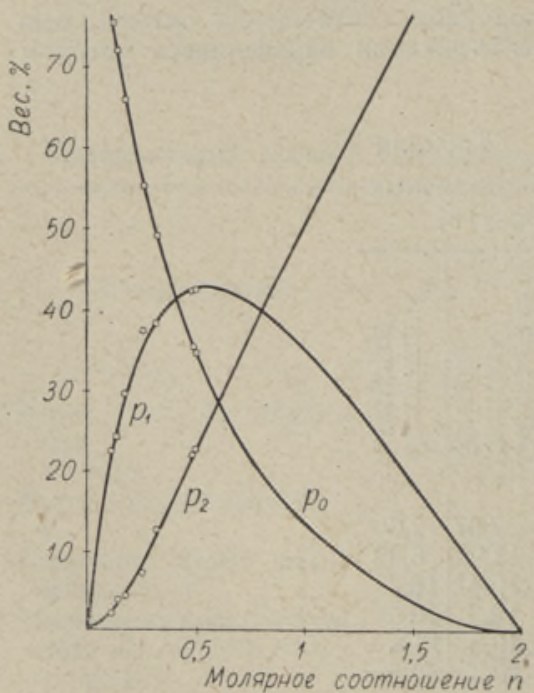
фиг. 2, показывают, что опытные результаты хорошо совпадают с расчетными. Это указывает на то, что кинетическне уравнения могут быть применены для расчета состава системы, несмотря на частичную полимеризацию олефинов. Однако полученное соотношение между $k_{1} / k_{2}=1: 1,1$ не является истинным соотношением констант скорости образования моно- и диоктилбензола, а представляет собой соотношение между константой скорости образования монооктилбензола и средней константой скорости образования диоктилбензола и моноалкилбензола димера октена-1.

Истинное соотношение между константами скоростей образования диоктилбензола и монооктилбензола $\left(k_{1} / k_{2}\right)$ или реакционная способность октилбензола по сравнению с бензолом будет меньше, т. к. истинное количество диоктилбензола во всех алкилатах меньше рассчитанного. Образование моноалкилбензола димера октена имеет 
существенное значение, так как удельный вес реакций полимеризации (димеризации и тинмеризации) значительный.

Суммируя полученные результаты с данными, полученными при совместном алкилировании бензола и октилбензола, можно прийти к заключению, что реакционная способность октилбензола в реакциях алкилирования ядра алкенами меньше, чем реакцнонная способность бензола.

\section{Л И ТЕР А Т У Р A}

1. Н. Н. Лебедев, Реакционная способность ароматических соединений при их алкилировании, ЖОХ 1957, № 9, стр. 2461 .

2. A. I. B r o w n,..M. J. Gr a y s o n, Am. Chem. Soc. $75,1953,6285$.

3. В. Г. Плюснин, О закономерностях образования алкилбензолов в процессе алкилирования. Хим. перераб. нефт. углеводородов. Тр. Всесоюз. Совещ. Изд-во АН СССР, 1956, стр. 396.

4. Состояние теории химического строения в органической химии. Стен. отчет Всесоюз. Совещ. Изд-во АН СССР, 1952.

5. F. E. C on d o n, Relative rales of propylation of monoalkyl benzenes, J. Am. Chem. Soc., $1948,70,2265$.

6. N. L. B r o w n, H. J u n g k, The reaction of benzene and toluene with ethyl, isopropyl and t-butylbromider under influence of $\mathrm{AlBr}_{3}$. J. Am. Chem. Soc. 78, 1956, No. 10, 2182.

7. H. Jungk, C. K. S mook, H. C. B r ow n, Kinetics of metylation and etylation of benzene and toluene in 1,2,4-triclorbenzene and under the influence of $\mathrm{AlBr}_{3}$, J. Am. Chem. Soc. 78, 1956, No. 10, 2185.

8. Н. Н. Леб́ едев, Кинетика реакции алкилирования бензола, ЖОХ 1954, № 4, cтp. 664.

9. B. A. B r ow n, J. Am. Chem. Soc. 77, 1955, 5584.

10. Н, Н. П ебедев, И. И. Ба т адж и, Научн. доклад высш. Шк. Химия и хим. технология, 1958, № 1, стр. 104.

11. В. Г. Плюснин, Н. М. Р одигин, Закономерности замещения атомов водорода в бензольном ядре алкильными группа̨ми, Ж. физ. хим. 31, 1957, № 9, стр. 2066.

12. В. Г. Плюснин, Фтористый водород как катализатор реакций алкилирования и полимеризаций, Докт. дисс., Свердловск, 1953.

13. А. П. Л ысенк о, Получение диалкилбензолов алкилированием изопропилбензола олефинами в присутствии фтористого водорода, Канд. дисс. Свердловск, 1958.

14. C. K. I n g o I d, Influence of directing groups of nuclear reactivity in oriented aromatic substitutions, J. Chem. Soc., 1931, No. 8, p. 1959.

Ннститут кимии

Академии наук Эстопской ССР
Поступила в редакцию

19. XII 1961

\section{OKTUUULBENSOOLI REAGEERIMISVÕIME}

\section{H. Voore}

\author{
S. Faingold, \\ tehniliste teaduste kandidaat
}

\section{Resümee}

Artiklis avaldatakse uurimistulemused oktüülbensooli reageerimisvõime kohta normaalsete olefiinidega alküleerimisreaktsioonis $\mathrm{AlCl}_{3}$ katalüsaatori juuresolekul ning monningad seaduspärasused bensooli alküleerimisel 1-okteeniga.

Oktüülbensooli reageerimisvõime määrati alküleerimisel 1-okteeniga ja 1-penteeniga.

Uurimine näitas, et oktüülrühma sisseviimise korral väheneb alküleerimisel bensooli tuuma reageerimisvōime kōrgemate alkeenidega. 
Bensooli alküleerimisel 1-okteeniga kaasnevad mono- ja dioktüülbensooli moodustumise reaktsioonile 1-okteeni -polümeriseerumise reaktsioonid. Seetōttu väheneb 1-okteen-bensooli moolsuhte suurendamise korral mono-oktüülbensooli saagis polümeersete produktide moodustumise arvel järsult.

\title{
Eesti NSV Teaduste Akadeemia Keemia Instituut
}

Saabus toimetusse

19. XII 1961

\section{THE REACTIVITY OF OCTYL-BENZOL}

\author{
H. Voore, S. Faingold
}

\section{Summary}

The authors present the results of their researches on the reactivity of octyl-benzol at the alkylation reaction with normal olefins in the presence of a catalyst $\mathrm{AlCl}_{3}$ and on some regularities in the process of alkylation of benzol with 1-octane.

The reactivity of octyl-benzol was defined at alkylation with 1-octane and 1-pentane.

The results of the researches have shown that in the case of an introduction of the octyl group during alkylation, the reactivity of the benzol nucleus to higher alkanes decreases.

At the alkylation with 1-octane, the reaction of the formation of mono- and dioctylbenzol is accompanied by reactions of 1-octane polymerization. Therefore, in the case of an increase of the molar ratio of 1-octane-benzol, the yield of mono-octyl-benzol decreases sharply at the expense of the formation of polymerization products.

Academy of Sciences of the Estonian S.S.R.,

Received Institute of Chemistry

Dec. 19th, 1961 